\title{
US MEDICAL STUDENTS' WILLINGNESS TO OFFER THE HPV VACCINE BY VACCINATION STATUS
}

\author{
Abbey B. Berenson, MD, PhD, Jacqueline M. Hirth, PhD, MPH, Erika L. Fuchs, PhD, MPH, \\ and and the Multidisciplinary Translation Team on Reproductive Women's Health \\ Center for Interdisciplinary Research in Women's Health, The University of Texas Medical Branch, \\ Galveston, Texas, 301 University Boulevard, Galveston, Texas 77555-0587, United States
}

\begin{abstract}
We surveyed third-year medical students to assess whether personal vaccination status was associated with willingness to recommend the human papillomavirus vaccine to patients. A total of 231 students completed an anonymous survey evaluating their knowledge, attitudes, and personal vaccine history. Of 122 female students, 81 (66.4\%) reported initiating the vaccine, as did 16 of 109 males (14.7\%). Females and students $\leq 25$ years old were more likely to be vaccinated. Knowledge did not vary by vaccination status, but anticipated behaviors did. Vaccinated students reported greater willingness to vaccinate adolescents before $15-16$ years of age $(92.1 \%$ vs. $78.6 \%, \mathrm{p}=0.008)$ and discuss vaccination at any type of medical visit (100\% vs. $89.7 \%, \mathrm{p}<0.001)$. Our findings suggest that prior experiences with the HPV vaccine may influence a provider's future actions. Thus, interventions that increase awareness of this relationship as well as vaccination rates among health care students may be beneficial.
\end{abstract}

\section{Keywords}

human papillomavirus (HPV); HPV vaccine; medical students; cancer prevention; attitudes; selfcare

\section{Introduction}

Human papillomavirus (HPV) infection is the most common sexually transmitted infection in the United States (US) [1]. Some strains of HPV cause genital warts and others can lead to anogenital and oropharyngeal cancers. Infection can be prevented by the HPV vaccine, but many eligible patients in the US have not been vaccinated. In fact, only $24 \%$ of boys and $41 \%$ of girls aged $13-17$ years completed all doses as of 2015 [2]. Increasing the number of providers who strongly recommend vaccination to their patients may be an effective way to

Correspondence and requests for reprints should be addressed to: Dr. Abbey Berenson, Center for Interdisciplinary Research in Women's Health, Department of Obstetrics and Gynecology, The University of Texas Medical Branch, 301 University Boulevard, Galveston, Texas 77555-0587, Telephone: 409-772-2417, Fax: 409-747-5129, abberens@utmb.edu.

Publisher's Disclaimer: This is a PDF file of an unedited manuscript that has been accepted for publication. As a service to our customers we are providing this early version of the manuscript. The manuscript will undergo copyediting, typesetting, and review of the resulting proof before it is published in its final citable form. Please note that during the production process errors may be discovered which could affect the content, and all legal disclaimers that apply to the journal pertain.

Conflicts of Interest Statement: The authors do not have any commercial or other associations that might pose a conflict of interest. 
address this problem as strong physician recommendation has been associated with vaccination $[3,4]$.

To accomplish this, it is critical to determine factors that can affect providers' HPV vaccination practices. One important factor is their attitude toward vaccination as attitudes have been shown to predict recommendation behavior even more strongly than professional guidelines [5]. Physicians' personal experience with HPV vaccination may also shape their commitment as this has been shown for other health practices. For example, physicians who reported actively promoting breastfeeding to patients had themselves breastfed longer than physicians who denied promoting breastfeeding [6]. Additionally, patients whose physicians have been vaccinated against influenza were more likely to receive this vaccine than patients of unvaccinated physicians [7].

It is difficult to examine the relationship between recommending the HPV vaccine and personally receiving it among practicing physicians as few were young enough to be eligible for the vaccine when it was first approved in the US in 2006 [8]. Most medical students, however, are young enough to have been vaccinated. In the US, the cohorts recommended for HPV vaccination are females born in 1980 or later and males born in 1990 or later. To date, few data are available on vaccine uptake among US medical students and whether uptake impacts attitudes or practices [9]. To address this, our study investigated the relationship between the vaccination status of US medical students and their knowledge, attitudes, and anticipated behaviors related to HPV vaccination.

\section{Methods}

After obtaining informed consent, we administered an anonymous, voluntary, 1-page survey to multiple groups of third-year medical students from November 4, 2015 to November 23, 2016 during their obstetrics/gynecology clinical rotation at the University of Texas Medical Branch in Galveston (UTMB). The 5-10 minute survey was developed by the first author and assessed HPV vaccination status, HPV vaccine knowledge, and attitudes about offering the vaccine in different settings. Participants were allowed to choose a small gift, such as a reusable lunch bag or plastic cup from a gift basket, as compensation for their participation.

Students who answered a question about how many HPV shots they have received were included in this study. Knowledge was determined by responses of "agree" or "disagree" to 11 factual statements about HPV and HPV vaccination. Attitudes and anticipated behaviors were assessed by responses of "agree" or "disagree" to 19 belief or behavior statements. These statements addressed willingness to offer the vaccine at every opportunity, to patients less than 15-16 years old, to patients as young as 9 years of age, and in non-traditional settings, such as specialized care clinics or in schools. Other statements addressed comfort with discussing adolescent sexuality with parents, the safety and benefits of vaccination, and the amount of time needed to discuss vaccination with parents.

Bivariate comparisons were performed, comparing knowledge and attitudes by student vaccination status, using chi-squared tests or Fisher's exact tests, as appropriate. Analyses were performed using SAS statistical software version 9.3 (Cary, NC); p values $<0.05$ were 
considered significant. All procedures were approved by the UTMB institutional review board.

\section{Results}

A total of 231 medical students completed the survey. Most students were $\leq 25$ years old (70.6\%) and female (52.8\%) (Table 1). Most participants had not been vaccinated against HPV: $58 \%$ reported they had never received any dose of the HPV vaccine. Vaccinated students (those who had received $\geq 1$ dose) tended to be younger ( $\leq 25$ years old) and female. On average, those vaccinated against HPV received their first dose at 17.6 years of age (SD 4.0). Most students who had initiated HPV vaccination also completed it $(81.4 \%$ received 3 doses).

Nearly all students (95\%) correctly disagreed with the statement "Most people with genital HPV infections have symptoms" and correctly agreed with "Side effects of the HPV vaccine are minor" (Table 2). The lowest correct response rate (25.1\%) was for the statement "If a patient received only 1 HPV vaccine dose $>1$ year ago, they should restart the 3 -dose series." For each of the other 10 factual statements, $\geq 50 \%$ of students had the correct response. We detected no difference in knowledge between vaccinated and unvaccinated students.

Students were also queried on whether they agreed with 19 different statements that addressed beliefs and anticipated behaviors with patients. Of these, 221 of the 231 students agreed with the statement "I would recommend the HPV vaccine to eligible patients in my practice." There was no difference in responses between vaccinated and unvaccinated students for 15 of the 19 statements (Table 3).

Responses varied by vaccination status for four statements of behavior. Unvaccinated students were more likely to agree with the statement "I prefer to wait until the child is 1516 yo before I recommend the HPV vaccine." Conversely, vaccinated students indicated greater willingness to vaccinate 9- or 10-year-old patients. Furthermore, responses from vaccinated students indicated greater willingness to discuss HPV vaccination with patients seeking care for other issues and those seeking care for chronic conditions. Thus, vaccinated students appeared to have a stronger commitment to HPV vaccination at every eligible patient encounter than unvaccinated students.

\section{Discussion}

In this study, less than half of the medical students we surveyed reported having personally initiated HPV vaccination. This finding is similar to that observed among medical and physician assistant students attending a school in a different region of the US [9] and so may be representative of many parts of the country. We observed that many more female than male medical students were vaccinated; this is likely due to the fact that the Centers for Disease Control and Prevention (CDC) did not recommend HPV vaccination for males until 2011 [8]. The rates of vaccination we observed do surpass national rates of HPV vaccination for young adults in the US (66.4\% of females in our study vs. $40.2 \%$ of US females ages 19 $-26 ; 14.7 \%$ of males in our study vs $8.2 \%$ of US males ages $19-26$ ) [10], but they are still well below the CDC's target of an $80 \%$ vaccination rate by 2020 [11]. Even though medical 
students are a well- educated population involved in healthcare, there is still a need for interventions to increase HPV vaccine uptake among them.

The majority of students demonstrated high levels of knowledge and expressed positive opinions about HPV vaccination. However, some participants had concerns about their ability to speak about HPV vaccination with parents and the amount of time needed to discuss it. These are serious concerns as they are known barriers to recommending vaccination $[12,13]$.

Some important differences were observed in anticipated behaviors among medical students who did and did not report HPV vaccination. Unvaccinated students reported they may delay recommendation of the HPV vaccine until patients are 15 - 16 years old, suggesting that they are less likely than vaccinated students to discuss vaccination at the ages recommended by the CDC [14]. Conversely, HPV-vaccinated medical students were more likely to report they would recommend the vaccine for patients as young as age 9 and less likely to wait until ages 15 or 16 . This is encouraging as it may help with the current problem that many US physicians do not strongly endorse HPV vaccination for younger adolescents [15]. Vaccinated students were also more willing to discuss HPV vaccination when patients were seen for other problems or chronic conditions. This demonstrates that they are more likely to follow the CDC's recommendation to use every opportunity to offer the HPV vaccine [16]. By eliminating a separate vaccination-only visit, this practice would assist parents of patients with chronic conditions who face considerable time and financial pressures associated with frequent healthcare visits. This study has some limitations. We relied upon self-report of HPV vaccination, which may be subject to recall bias. Additionally, because the medical students were rotating in the obstetrics/gynecology department at the time of the survey, social desirability may have also introduced bias. We also cannot assume causality between self-reported HPV vaccination and HPV-related knowledge and opinions as this study was not prospective. Finally, as third-year medical students have limited experience with patient care, the opinions and anticipated behaviors observed in this study may change once they begin independent patient care.

\section{Conclusions}

As the physicians of tomorrow, many medical students will soon have direct influence over the vaccination behaviors of others. We observed that medical students' personal HPV vaccination status correlates with their commitment to CDC recommendations for patient vaccination. This finding is consistent with prior reports linking physician participation in health practices with similar participation by their patients $[6,7]$. Thus, campaigns focused on increasing HPV vaccination among medical students might be an effective way to increase the number of HPV vaccines administered at the CDC-recommended ages. Furthermore, the possibility that personal experience with the HPV vaccine could influence future actions as a provider suggests that medical students may need to be educated on the existence of such personal biases. 


\section{Acknowledgments}

Members of the Multidisciplinary Translation Team on Reproductive Women's Health who are not included as named authors are Dr. Richard Rupp and Dr. Yong- Fang Kuo of UTMB and Dr. Kwabena Sarpong of Baylor College of Medicine. Susan Y. Rojahn, PhD, of UTMB assisted with manuscript preparation.

Financial Support: Support for this study was provided by a prevention grant from the Cancer Prevention \& Research Institute of Texas (CPRIT) (PP150004, Berenson, PD) and by the Institute for Translational Sciences at the University of Texas Medical Branch though a Clinical and Translational Science Award (UL1 TR001439) from the National Center for Advancing Translational Sciences at the National Institutes of Health (NIH) Dr. Fuchs is supported by a research career development award (K12HD052023: Building Interdisciplinary Research Careers in Women's Health-BIRCWH; Berenson, PI) from the Office of Research on Women's Health and the Eunice Kennedy Shriver National Institute of Child Health and Human Development of the NIH. The content is solely the responsibility of the authors and does not necessarily represent the official views of CPRIT, the NIH, or any institute therein.

\section{References}

1. Satterwhite CL, Torrone E, Meites E, Dunne EF, Mahajan R, Ocfemia MC, et al. Sexually transmitted infections among US women and men: prevalence and incidence estimates, 2008. Sex Transm Dis. 2013; 40:187-193. [PubMed: 23403598]

2. Reagan-Steiner S, Yankey D, Jeyarajah J, Elam-Evans LD, Curtis CR, MacNeil J, et al. National, Regional, State, and Selected Local Area Vaccination Coverage Among Adolescents Aged 13-17 Years - United States, 2015. MMWR Morb Mortal Wkly Rep. 2016; 65:850-858. [PubMed: 27561081]

3. Wilson AR, Hashibe M, Bodson J, Gren LH, Taylor BA, Greenwood J, et al. Factors related to HPV vaccine uptake and 3-dose completion among women in a low vaccination region of the USA: an observational study. BMC Womens Health. 2016; 16:41. [PubMed: 27449775]

4. Rosenthal SL, Weiss TW, Zimet GD, Ma L, Good MB, Vichnin MD. Predictors of HPV vaccine uptake among women aged 19-26: importance of a physician's recommendation. Vaccine. 2011; 29:890-895. [PubMed: 20056186]

5. Kulczycki A, Qu H, Shewchuk R. Primary Care Physicians' Adherence to Guidelines and Their Likelihood to Prescribe the Human Papillomavirus Vaccine for 11- and 12-Year-Old Girls. Womens Health Issues. 2016; 26:34-39. [PubMed: 26344447]

6. Sattari M, Levine D, Neal D, Serwint JR. Personal breastfeeding behavior of physician mothers is associated with their clinical breastfeeding advocacy. Breastfeed Med. 2013; 8:31-37. [PubMed: 23373434]

7. Godoy P, Castilla J, Mayoral JM, Martin V, Astray J, Torner N, et al. Influenza vaccination of primary healthcare physicians may be associated with vaccination in their patients: a vaccination coverage study. BMC Fam Pract. 2015; 16:44. [PubMed: 25880501]

8. Markowitz LE, Tsu V, Deeks SL, Cubie H, Wang SA, Vicari AS, et al. Human papillomavirus vaccine introduction--the first five years. Vaccine. 2012; 30(Suppl 5):F139-F148. [PubMed: 23199957]

9. Suryadevara M, Bonville JR, Kline RM, Magowan C, Domachowske E, Cibula DA, et al. Student HPV vaccine attitudes and vaccine completion by education level. Hum Vaccin Immunother. 2016; 12:1491-1497. [PubMed: 26836052]

10. Williams WW, Lu PJ, O'Halloran A, Kim DK, Grohskopf LA, Pilishvili T, et al. Surveillance of Vaccination Coverage Among Adult Populations - United States, 2014. MMWR Surveill Summ. 2016; 65:1-36.

11. U.S. Department of Health and Human Services OoDPaHP. Healthy People 2020.

12. Holman DM, Benard V, Roland KB, Watson M, Liddon N, Stokley S. Barriers to human papillomavirus vaccination among US adolescents: a systematic review of the literature. JAMA Pediatr. 2014; 168:76-82. [PubMed: 24276343]

13. Bynum SA, Staras SA, Malo TL, Giuliano AR, Shenkman E, Vadaparampil ST. Factors associated With Medicaid providers' recommendation of the HPV vaccine to low-income adolescent girls. JAdolescHealth. 2014; 54:190-196. 
14. Petrosky E, Bocchini JA Jr, Hariri S, Chesson H, Curtis CR, Saraiya M, et al. Use of 9-Valent Human Papillomavirus (HPV) Vaccine: Updated HPV Vaccination Recommendations of the Advisory Committee on Immunization Practices. MMWR MorbMortalWklyRep. 2015; 64:300304.

15. Gilkey MB, Malo TL, Shah PD, Hall ME, Brewer NT. Quality of physician communication about human papillomavirus vaccine: findings from a national survey. Cancer Epidemiol Biomarkers Prev. 2015; 24:1673-1679. [PubMed: 26494764]

16. Centers for Disease Control and Prevention. [accessed November 22, 2016] Human Papillomavirus (HPV) - Clinician Factsheets. 2015. http://www.cdc.gov/hpv/hcp/clinician-factsheet.html 


\section{Highlights}

- $\quad$ Less than $50 \%$ of third-year medical students at a Texas university had initiated the HPV vaccine.

- Unvaccinated students indicated they prefer to wait until age 15 or 16 to offer the vaccine.

- Vaccinated students had greater commitment to recommending the vaccine at every opportunity. 


\section{Table 1}

Participant Characteristics (N=231)

\begin{tabular}{|c|c|c|c|c|}
\hline Characteristics & Total N(\%) ${ }^{a}$ & $\begin{array}{l}\text { Vaccinated } \\
\quad \mathbf{n}(\%)^{b}\end{array}$ & $\begin{array}{l}\text { Unvaccinated } \\
\mathrm{n}(\%)^{b}\end{array}$ & p-value \\
\hline \multicolumn{5}{|l|}{ Age } \\
\hline$\underline{25}$ & $163(70.6)$ & $77(47.2)$ & $86(52.8)$ & 0.01 \\
\hline$\geq 26$ & $68(29.4)$ & $20(29.4)$ & $48(70.6)$ & \\
\hline \multicolumn{5}{|l|}{ Gender } \\
\hline Male & $109(47.2)$ & $16(14.7)$ & $93(85.3)$ & $<0.001$ \\
\hline Female & $122(52.8)$ & $81(66.4)$ & $41(33.6)$ & \\
\hline \multicolumn{5}{|l|}{ Race/ ethnicity } \\
\hline Hispanic & $37(16.0)$ & $16(43.2)$ & $21(56.8)$ & 0.32 \\
\hline White & $130(56.3)$ & $59(45.4)$ & $71(54.6)$ & \\
\hline Black & $14(6.1)$ & $7(50.0)$ & $7(50.0)$ & \\
\hline Other/ unknown & $50(21.6)$ & $15(30.0)$ & $35(70.0)$ & \\
\hline \multirow[t]{2}{*}{ Received at least $1 \mathrm{HPV}$ shot } & $97(42.0)$ & & & \\
\hline & Mean (SD) & & & \\
\hline Age when 1st HPV shot received ${ }^{c}$ & $17.6(4.0)$ & & & \\
\hline "Vaccinated" indicates at least one do & of the HPV va & cine was rece & ved. Boldface ind & icates sign \\
\hline \multicolumn{5}{|l|}{${ }^{a}$ Column percents are shown } \\
\hline \multicolumn{5}{|l|}{$b$ Row percents are shown } \\
\hline
\end{tabular}

Vaccine. Author manuscript; available in PMC 2018 March 01. 


\section{Table 2}

Frequencies reflecting medical student knowledge about the HPV vaccine. $(\mathrm{N}=231)$

\begin{tabular}{|c|c|c|c|c|}
\hline & $\begin{array}{l}\text { Total } \\
\text { n }(\%) \text { correct }\end{array}$ & $\begin{array}{l}\text { Vaccinated, } \\
\text { n }(\%) \text { correct }\end{array}$ & $\begin{array}{l}\text { Unvaccinated, } \\
\text { n }(\%) \text { correct }\end{array}$ & p-value \\
\hline Statements of fact $a, b$ & & $\mathrm{n}=97$ & $\mathrm{n}=134$ & \\
\hline Almost all cervical cancers are caused by HPV infection. (A) $(n=223)$ & $196(87.9)$ & $84(89.4)$ & $112(86.8)$ & 0.57 \\
\hline $\begin{array}{l}\text { The prevalence of HPV infection is highest among women in their 30s.(D) } \\
(n=210)\end{array}$ & $112(53.3)$ & $52(55.9)$ & $60(51.3)$ & 0.5 \\
\hline Most people with genital HPV infections have symptoms. (D) $(n=228)$ & $217(95.2)$ & $93(95.9)$ & $124(94.7)$ & $0.23^{c}$ \\
\hline $\begin{array}{l}\text { Genital warts are caused by the same HPV types that cause cervical cancer. } \\
\text { (D) }(n=223)\end{array}$ & $176(78.9)$ & $72(78.3)$ & $104(79.4)$ & 0.84 \\
\hline $\begin{array}{l}\text { Sexually active women should be tested for HPV before getting the HPV } \\
\text { vaccine. (D) }(n=208)\end{array}$ & $152(73.1)$ & $68(75.6)$ & $84(71.2)$ & 0.48 \\
\hline $\begin{array}{l}\text { Women who have been diagnosed with HPV infection should not be given } \\
\text { the HPV vaccine. (D) }(n=189)\end{array}$ & $159(84.1)$ & $74(87.1)$ & $85(81.7)$ & 0.32 \\
\hline $\begin{array}{l}\text { If a patient received only } 1 \mathrm{HPV} \text { vaccine dose }>1 \text { year ago, they should } \\
\text { restart the } 3 \text {-dose series. (D) }(n=175)\end{array}$ & $44(25.1)$ & $19(23.5)$ & $25(26.6)$ & 0.63 \\
\hline $\begin{array}{l}\text { The HPV vaccine is FDA approved for women up to } 30 \text { years of age. (D) } \\
(n=194)\end{array}$ & $102(52.6)$ & $47(54.6)$ & $55(50.9)$ & 0.61 \\
\hline $\begin{array}{l}\text { White women have the highest incidence of cervical cancer in the US. (D) } \\
(n=165)\end{array}$ & $98(59.4)$ & $47(61.8)$ & $51(57.3)$ & 0.55 \\
\hline $\begin{array}{l}\text { Physician recommendation is the most important facilitator for HPV } \\
\text { vaccination. (A) }(n=222)\end{array}$ & $195(87.8)$ & $78(83.9)$ & $117(90.7)$ & 0.12 \\
\hline Side effects of the HPV vaccine are minor. (A) $(n=222)$ & $212(95.5)$ & $89(95.7)$ & $123(95.4)$ & $0.25^{c}$ \\
\hline
\end{tabular}

HPV - human papillomavirus; A - Agree; D - Disagree. "Vaccinated" indicates at least one dose of the HPV vaccine was received. Number of respondents indicated in parentheses after the statement.

a Denominator may vary due to missing responses.

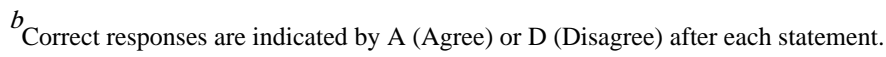

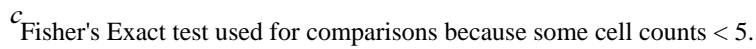


Table 3

Frequencies reflecting medical student opinions about the HPV vaccine $(\mathrm{N}=231)$.

\begin{tabular}{|c|c|c|c|c|}
\hline & $\begin{array}{l}\text { Total n } \\
(\%) \text { agree }\end{array}$ & $\begin{array}{l}\text { Vaccinated } \\
(\%) \text { agree }\end{array}$ & $\begin{array}{l}\text { Unvaccinated } \\
(\%) \text { agree }\end{array}$ & p-value \\
\hline Statements of belief or behavior ${ }^{a}$ & & $\mathrm{n}=97$ & $\mathrm{n}=134$ & \\
\hline $\begin{array}{l}\text { Providers should use every opportunity to recommend the HPV vaccine to eligible } \\
\text { patients. }(\mathrm{n}=226)\end{array}$ & $216(95.6)$ & $94(97.9)$ & $122(93.8)$ & $0.09^{b}$ \\
\hline I am comfortable discussing adolescent sexuality with parents. $(\mathrm{n}=205)$ & $171(83.4)$ & $74(86.0)$ & $97(81.5)$ & 0.39 \\
\hline I would recommend the HPV vaccine to eligible patients in my practice. (n=223) & $221(99.1)$ & $94(100.0)$ & $127(98.4)$ & $0.33^{b}$ \\
\hline I will give (gave) the HPV vaccine to my own child(ren). ( $\mathrm{n}=51$ ) & $50(98.0)$ & $18(100)$ & $32(97.0)$ & $0.65^{b}$ \\
\hline I think that HPV infection is serious enough to warrant a vaccine. $(n=228)$ & $220(96.5)$ & $94(96.9)$ & $126(96.2)$ & $0.27^{b}$ \\
\hline $\begin{array}{l}\text { I believe that the HPV vaccine encourages adolescents to have sexual intercourse. } \\
(\mathrm{n}=222)\end{array}$ & $7(3.2)$ & $1(1.0)$ & $6(4.8)$ & $0.09^{b}$ \\
\hline I don't know how to bring up the topic of HPVvaccination with parents. $(\mathrm{n}=217)$ & $26(12.0)$ & $8(8.5)$ & $18(14.6)$ & 0.17 \\
\hline I am comfortable discussing the benefits and risk of HPV vaccination. $(n=215)$ & $186(86.5)$ & $85(91.4)$ & $101(82.8)$ & 0.07 \\
\hline $\begin{array}{l}\text { I prefer to wait until the child is } 15-16 \text { years old before I recommend the HPV } \\
\text { vaccine. }(n=201)\end{array}$ & $31(15.4)$ & $7(7.9)$ & $24(21.4)$ & 0.008 \\
\hline $\begin{array}{l}\text { I am concerned about the amount of time needed to discuss HPV vaccination with } \\
\text { parents. }(\mathrm{n}=199)\end{array}$ & $34(17.1)$ & $16(18.2)$ & $18(16.2)$ & 0.71 \\
\hline I don't have much confidence in the safety of the HPV vaccine. $(n=210)$ & $9(4.3)$ & $5(5.6)$ & $4(3.3)$ & $0.20^{b}$ \\
\hline I am concerned that the HPV vaccine may cause Guillain-Barre syndrome. $(n=195)$ & $10(5.1)$ & $4(4.6)$ & $6(5.5)$ & $0.25^{b}$ \\
\hline I am concerned about the efficacy of the HPV vaccine. $(n=212)$ & $20(9.4)$ & $9(10.0)$ & $11(9.0)$ & 0.81 \\
\hline I would recommend the HPV vaccine to a relative. $(\mathrm{n}=212)$ & $202(95.3)$ & $90(94.7)$ & $112(95.7)$ & 0.74 \\
\hline $\begin{array}{l}\text { I am willing to discuss HPV vaccination when patients come in for other problems. } \\
(\mathrm{n}=216)\end{array}$ & $203(94.0)$ & $90(100)$ & $113(89.7)$ & $<0.001 b$ \\
\hline $\begin{array}{l}\text { I am willing to discuss HPV vaccination when patients are seen for chronic } \\
\text { conditions. }(\mathrm{n}=173)\end{array}$ & $199(93.4)$ & $91(98.9)$ & $108(89.3)$ & $\mathbf{0 . 0 0 3}^{b}$ \\
\hline I would recommend giving the HPV vaccine to a 9-10 year old patient. ( $\mathrm{n}=173$ ) & $100(57.8)$ & $49(70.0)$ & $51(49.5)$ & 0.007 \\
\hline I feel that giving the HPV vaccine in schools is a good idea. $(\mathrm{n}=183)$ & $141(77.0)$ & $58(79.4)$ & $83(75.4)$ & 0.53 \\
\hline $\begin{array}{l}\text { I feel that patient navigation is an effective way to decrease barriers related to HPV } \\
\text { vaccination. }(n=181)\end{array}$ & $177(97.8)$ & 80 (97.6) & $97(98.0)$ & $0.37^{b}$ \\
\hline
\end{tabular}

"Vaccinated" indicates at least one dose of the HPV vaccine was received. Boldface indicates significance. Number of respondents indicated in parentheses after the statement.

${ }^{a}$ Denominator may vary due to missing responses.

${ }^{b}$ Fisher's Exact test used for comparisons because some cell counts $<5$. 